\title{
A vivência no trânsito e as implicaçóes na saúde dos motoristas de autocarros: estudo fenomenológico descritivo
}

The experience in traffic and its effects on the health of bus drivers: a phenomenological descriptive study

La experiencia en el tránsito y las implicaciones para la salud de los conductores de autobuses: estudio fenomenológico descriptivo

Vanessa Carine Gil de Alcantara*iD; Rose Mary Costa Rosa Andrade Silva** (D); Eliane Ramos Pereira** (DD;

Dejanilton Melo da Silva**** iD; Isadora Pinto Flores***** (DD

\section{Resumo}

Enquadramento: $\mathrm{O}$ quotidiano do motorista de autocarros é dinâmico. Muitas variáveis o cercam: a habilidade na conduçáo e de controlar os seus medos e o cumprimento correto do seu itinerário. As limitaçóes e desafios vivenciados podem desencadear um processo de sofrimento psíquico.

Objetivo: Descrever as perceçóes dos motoristas de autocarros acerca da vivência no trânsito e os possíveis efeitos do quotidiano da mobilidade urbana nos motoristas.

Metodologia: Estudo descritivo fenomenológico, pautado no pensamento de Maurice Merleau-Ponty, realizado num terminal rodoviário de autocarros, no período de julho a dezembro de 2017. Entrevistaram-se 24 motoristas de autocarros através de perguntas abertas.

Resultados: Emergiram duas categorias: O trânsito é uma caixa de surpresas e $\mathrm{O}$ equilíbrio psicológico é necessário. Conclusáo: Dar voz a estes profissionais, trazendo à luz o que acarreta o seu sofrimento, e reconhecer as suas necessidades, contribuirá para a prevençáo de doenças físicas e psicológicas, bem como de acidentes de trânsito. Os motoristas rodoviários carecem de melhores condiçôes para poderem colocar a cidade em movimento diariamente.

Palavras-chave: consciência; motoristas; trânsito; doenças profissionais; stress psicológico; pesquisa qualitativa

\section{Abstract}

Background: The daily life of bus drivers is dynamic and influenced by many variables: their driving skills, their ability to overcome their fears, and their ability to follow an established itinerary. Bus drivers experience limitations and challenges that can trigger a process of psychological distress.

Objective: To describe the perceptions of bus drivers about their experience in traffic and the possible effects of daily urban mobility on these drivers.

Methodology: Descriptive, phenomenological study based on the work of Maurice Merleau-Ponty. It was conducted at a bus station between July and December 2017. Twenty-four bus drivers were interviewed using open-ended questions.

Results: Two categories emerged: Traffic is a box full of surprises and Psychological balance is necessary.

Conclusion: Giving a voice to these professionals, bringing to light what causes their suffering, and recognizing their needs will contribute to the prevention of physical and psychological disorders, as well as traffic accidents. Bus drivers need better conditions to set the city in motion on a daily basis.

Keywords: conscience; drivers; traffic; occupational diseases; stress, psychological; qualitative research

*Lic., Psicóloga. Doutoranda em Ciências do Cuidado em Saúde, Universidade Federal Fluminense, Escola de Enfermagem Aurora Afonso Costa, 24020-091, Niterói, Brasil [vanessagilpsi-
cologa @hotmail.com]. (D https:///orcid.org/0000-0002-8508-0163. Contribuição no artigo: concepção do projeto, pesquisa bibliográfica, colheita e análise de dados, discussão, redação
do artigo. Morada para correspondência: Rua Doutor Celestino, $74,6^{\circ}$ andar, Centro, Niterói, 24020-091, Rio de Janeiro, Brasil. **Ph.D., Enfermeira, Professora Associada, Universidade Federal Fluminense, Escola de
Enfermagem Aurora Afonso Costa 24020-091, Niterói RJ, Brasil [roserosauff $@$ amail.com]. Enfermagem Aurora Afonso Costa, 24020-091, Niteroi RJ, Brasil roserosauff@agmail.com]. discussão, redação do artigo.

**s:ph.D. Enfermeira, Professora Associada, Universidade Federal Fluminense, Escola de Enfermagem Aurora Afonso Cosso $24020-091$, Niterói RI Bmil [elianeramos uff@erailcom] magem Aurora Afonso Costa, 24020-091, Niteroi kj, Brasi (elianeramos.uff@gmail.com]. https://orcid.org/0000-0002-6381-3979. Contribuição no artigo: discussão e redação do artigo. ***:* Ph.D., Entermeiro, Professor, Universidade Federal Fluminense, Escola de Enfer magem Aurora Afonso Costa, 24020-091, Niteroi Rj, Brasil [demedasi@@gmail.com. . (D) https://Orcid.org/0000-0002-0800-3658. Cont
discussão, normalização e redação do artigo.

*.scussão, normalizaçáa e redação do artigo. gem Aurora Afonso Costa, 24020-091, Niterói RJ, Brasil [isadoraflores@outlook.com gem Aurora Afonso Costa, 24020-091, Niteroi k, Brasil [isadoraflores@outlook.com discussão e redação do artigo.

\section{Resumen}

Marco contextual: La vida diaria del conductor de autobús es dinámica. Existen muchas variables a su alrededor: su capacidad para conducir y controlar sus miedos y el correcto cumplimiento de su itinerario. Las limitaciones y los desafíos experimentados pueden desencadenar un proceso de sufrimiento psicológico.

Objetivo: Describir las percepciones de los conductores de autobuses sobre la experiencia en el tránsito y los posibles efectos de la movilidad urbana diaria en los conductores. Metodología: Estudio descriptivo fenomenológico, basado en el pensamiento de Maurice Merleau-Ponty, realizado en una terminal de autobuses, de julio a diciembre de 2017. Se entrevistó a 24 conductores de autobús mediante preguntas abiertas.

Resultados: Surgieron dos categorías: el tránsito es una caja de sorpresas y el equilibrio psicológico es necesario. Conclusión: Dar voz a estos profesionales, sacar a la luz las causas de sus sufrimientos y reconocer sus necesidades contribuirá a la prevención de las enfermedades físicas y psicológicas, así como de los accidentes de tráfico. Los conductores necesitan mejores condiciones para poder poner en marcha la ciudad a diario.

Palabras clave: conciencia; conductores; tráfico; enfermedades profesionales; estrés psicológico; investigación cualitativa 


\section{Introdução}

A atividade do motorista de autocarros acontece na realidade do trânsito: um espaço dinâmico e sistemático, que requer atenção difusa e cuidado. Esta profissão é universal, presente em diversas culturas. Nesta profissão, o trabalhador está exposto a variáveis que influenciam positiva ou negativamente a sua jornada de trabalho: vibrações sonoras agudas; vírus; temperaturas elevadas; privação alimentar; e à possibilidade de acidentes. $\mathrm{O}$ ambiente, por vezes, acaba por se tornar insalubre. Contudo, a principal exposição ocorre nas relaçóes interpessoais, que acontecem com os colegas de trabalho, a organização e os passageiros. O desgaste e stress resultantes deste trabalho podem alterar a saúde do profissional, tanto a nível físico e biológico quanto psíquico (Rajeshwar, Rajalakshmi, Nitin, \& Umadevi, 2016).

A saúde do trabalhador envolve, portanto, uma gama de dimensóes, que passam pela questão do seu próprio corpo e, por isso, são muitos os aspetos relacionados com a sua vida em sociedade, família e autocuidado (Silva et al., 2019). Neste caminho, é imprescindível, para o desenvolvimento e evolução preventiva da saúde do trabalhador, considerar a subjetividade e as relaçôes interpessoais. Destarte, as equipas de saúde e enfermagem do trabalho podem intervir com práticas educativas de prevenção a danos na saúde.

O trabalho em transportes coletivos é desgastante (Alcantara, Silva, Pereira, \& Silva, 2016), visto que as exigências do trabalho são uma ameaça para o próprio trabalhador. Fatores externos ao profissional podem ser ajustados para promover uma maior satisfação ao motorista. Desconsiderar esta situação quotidiana inviabiliza a promoção de condições favoráveis ao trabalho dentro dos autocarros, além de causar o desgaste físico e mental (Martins, Lopes, \& Farina, 2014). O setor de transporte de passageiros carece de práticas que visam a qualidade de vida e incentivos aos motoristas. Propiciar melhores condições de trabalho, infraestruturas como maior conforto nos bancos para os motoristas, climatização dos autocarros na cabine de direção, bem como incentivos salariais são diferenciais para superar o quotidiano do trânsito. É necessário o resgate da valorização profissional, caminho para a superação do stress.
Face ao exposto, esta pesquisa objetivou descrever as percepçóes dos motoristas de autocarros quanto à vivência no trânsito e os possíveis efeitos do quotidiano da profissão nos motoristas.

\section{Enquadramento}

Segundo dados da World Health Organization (WHO), o Brasil é o terceiro país na lista do trânsito que mais mata no mundo (WHO, 2013). Acidentes rodoviários são a principal causa de morte, lesão e internamento, resultando em altos custos económicos e sociais. A maioria (52\%) das pessoas mortas no tráfego são usuários rodoviários vulneráveis - peóes, motociclistas e ciclistas. Para remediar este facto, o Brasil tem avançado na construção de medidas preventivas e investido em campanhas de consciencialização acerca de práticas importantes para viagens seguras, como não falar ao telemóvel enquanto se conduz; uso regular do cinto de segurança; respeito da faixa de peóes; respeito de faixas exclusivas, sejam de transportes coletivos ou ciclovias; entre outras. No contexto do motorista de autocarros, a carga horária de trabalho em alguns países do mundo pode chegar a 56 horas semanais, o que pode ocasionar um número mais elevado de acidentes devido a esforço agudo. A Índia lidera no ranking de mortes no trânsito, e existem inúmeros estudos que evidenciam os impactos causados pelo trabalho, com avaliaçóes do estado de saúde de motoristas de autocarros através de exames, levando a diagnósticos de problemas de digestão, de visão, dores nas costas e irritação auditiva, além dos efeitos gerados pela poluição (Rajeshwar et al., 2016). Assim, entende-se que a dinâmica do trânsito urbano contribui para o aumento do cansaço e, também, do stress. Considera-se relevante destacar a carga horária do motorista no Brasil, país de origem do presente estudo, a qual é de 42 horas semanais.

O stress é um fator notadamente desfavorável aos motoristas de autocarros, uma vez que acabam por reforçar o sentimento de insatisfação para com a profissão. Além deste, o desrespeito pela ergonomia necessária para a realização do trabalho altera as dimensóes cognitivas e fisiológicas, ocasionando problemas diversos (Martins et al., 2014). A implementação de melhorias ergonómicas e o acolhimento às necessidades dos motoristas de autocarros são o início da 
valorização que esta classe trabalhadora tanto almeja. O seu quotidiano é dinâmico, e muitas variáveis o cercam: a habilidade na condução e de controlar os seus receios e, também, o cumprimento correto do itinerário. Neste contexto, estes profissionais prestam o serviço de transportar a população para diversos locais, seja de casa para o trabalho, para algum compromisso e vice-versa, somando, assim, mais uma variável de peso: o transporte seguro e responsável de vidas. Este dinamismo deveria ser refletido, do mesmo modo, em medidas de cuidado a estes profissionais. As limitações vivenciadas por estes, geralmente, não são consideradas pelas empresas onde trabalham, e o processo de sofrimento psíquico é negligenciado tanto pelo profissional quanto pela lógica organizacional. Este sofrimento psíquico pode ser silencioso ou invisivel, embora também possa eclodir de forma aguda por desencadeamento do contexto da atividade de conduzir. O stress torna-se excessivo devido ao longo período de permanência nesse estado, provocando desgastes físicos e psíquicos ao organismo, passando a ser disfuncional (Matos, Moraes, \& Pereira, 2015). Internamente, os profissionais necessitam de procurar recursos psíquicos para não influenciarem, negativamente, a mobilidade urbana.

A identificação, descrição e análise das queixas dos motoristas - afetados pelos factos do dia-a-dia - contribui para a disseminação das urgências vivenciadas por estes: a regulação dos assentos, a instalação de ar condicionado nos autocarros, a flexibilização da escala de trabalho, a hidratação correta e arejamento do autocarro nos dias quentes e o aquecimento do corpo para os dias frios, são algumas medidas simples, mas que fazem a diferença no trabalho do motorista, em qualquer parte do mundo (Ismail, Abdullah, Abdullah, \& Deros, 2015).

$\mathrm{Na}$ visão organizacional, o motorista de autocarros é condutor da máquina que conduz. Todavia, há necessidade de consideração dos processos físicos e psicológicos em questão no trabalho diário. $\mathrm{O}$ mundo profissional insere, assim, uma terceira responsabilidade: o cuidado ao motorista.

Para alcançar um cuidado amplo a esse referido trabalhador, é necessário olhar e conhecer, também, o que há de interno nele: a sua subjetividade. Assim, procura-se trazer o invisível à luz. $\mathrm{O}$ conhecimento transcende o físico; o corpo não detém o vivido, não o comporta; o corpo é mais do que reaçóes físicas, nervos e ossos. O visível é o que se apreende com os olhos; o sensível é o que se apreende sentindo (Merleau-Ponty, 2014). A incidência de dores na coluna, nos membros inferiores, dentre tantos outros, permite-nos pensar em melhorias no atendimento aos motoristas, o setor de enfermagem no trabalho deve ser responsável pela operacionalização da prática de atendimento na empresa.

Assim, deve-se implementar a educação em saúde, incentivando motoristas de autocarros a procurar cuidar de si e superar o receio do homem de procurar atendimento médico, por exemplo.

\section{Questóes de Investigação/Hipóteses}

Quais são as perceçôes dos motoristas de autocarros na vivência do trânsito, e quais as suas implicações para a saúde?

\section{Metodologia}

Este estudo é de abordagem qualitativa descritiva e o referencial é a fenomenologia de Maurice Merleau-Ponty. A pesquisa fenomenológica aproxima o histórico social do corporal e dos significados. Este referencial inovou o campo dos estudos do fenómeno e perceção ao considerar a perceção como conhecimento do corpo em si mesmo, anterior ao saber reflexivo (Carel \& Meacham, 2013). Portanto, a corporeidade detém a consciência e, nela, a perceção situa o corpo no mundo (Silva, 2017).

A escolha por este referencial metodológico deu-se pela liberdade de compreensão quanto à subjetividade envolvida na proposta deste trabalho. A fenomenologia assume outro lugar, onde o humano passa a ser considerado não somente como um uno, mas como um ser social, um ser em relação com o outro e com o mundo (Merleau-Ponty, 2014).

Os pesquisadores fenomenológicos questionam: "Qual a essência desse fenómeno? Como é experimentado por essas pessoas? O que significa?". A essência é o que faz um fenómeno ser o que é; sem ela, o fenómeno não seria o que é. A entrevista fenomenológica com perguntas abertas é a escuta que toca profundamente o corpo/espírito de outrem através de um silêncio persistente 
(Merleau-Ponty, como citado por Silva, 2017). O referencial fenomenológico permite ao investigador despir-se dos seus pré-conceitos e pré-conhecimento para, junto com o entrevistado, compreender o fenómeno a ser estudado, e compreendê-lo a partir do olhar do outro. É possível compreender o significado do fenómeno, da vivência, na entrevista fenomenológica (Giorgi, 2006).

A questão norteadora foi: Como vivencia o trânsito? Nessa modalidade de entrevista, o início dá-se a partir de uma questão que serve como guia no processo de colheita de dados, possibilitando respostas abertas (Dale, 1996). A entrevista fenomenológica é um método de investigação que permite o livre discurso, considera as simbolizaçóes do discurso, tornando-se uma ferramenta de riqueza de detalhes e, uma vez que no trânsito estão em ação inúmeros sentimentos e emoçôes e é muito dinâmico, através da fala dos participantes, rica em sentido, foi possível traduzir essas vivências, esses sentidos que estão constantemente latentes e muitas vezes sem condiçôes de serem compartilhados, dada a rotina desgastante e apressada destes profissionais.

Este estudo tem a aprovação da Comissão de Ética em Pesquisa do Hospital Universitário Antônio Pedro, da Faculdade de Medicina, com parecer número 2.131.165, em 21 de junho de 2017, sob o CAAE: 64110016.2.0000.5243. Foram seguidas as especificaçóes éticas e legais da Resolução 466/2012 do Conselho Nacional de Saúde.

As entrevistas aconteceram no terminal rodoviário de autocarros. A inclusão dos participantes deu-se pela técnica snowball, na qual um entrevistado comunica ao outro sobre a investigação e, assim, como uma bola de neve, o número de entrevistados cresce (Vinuto, 2014). O motorista era convidado a conhecer o estudo, e era feita a leitura do Termo de Consentimento Livre e Esclarecido (TCLE). Após aceite e assinado o TCLE, iniciava-se a entrevista na sala privativa do departamento de recursos humanos na empresa de autocarros. Cabe ressaltar que a pesquisa foi realizada com os motoristas que chegavam à garagem para encerrar a sua jornada diária de trabalho. Portanto, não foram contemplados todos os motoristas de autocarros ativos na garagem. O tempo médio de duração das entrevistas foi de 60 minutos, com a autorizaçáo dos participantes para o uso de gravador de áudio mp3. Foram feitas 24 entrevistas, não havendo perda amostral, pois, à medida que os motoristas conheciam os objetivos do estudo, dispunham-se a participar. Os critérios de inclusão da pesquisa foram participantes com mais de dois anos de profissão, que possuíssem mais de dois cursos de aprimoramento na função de motorista e que não tivessem estado afastados do trabalho por mais de cinco anos pelo Instituto Nacional do Seguro Social (INSS). Os critérios de exclusão foram motoristas que exerciam outra atividade remunerada e aqueles que, por algum motivo, não queriam participar.

A análise dos dados na investigação fenomenológica obedece quatro passos: o primeiro envolve a leitura criteriosa das transcrições da entrevista gravada dos participantes da investigação, conservando a linguagem do sujeito; neste segundo passo é possível entender que as declaraçôes dos participantes se reúnem para descrever as suas experiências e são semelhantes às dos demais participantes; o terceiro passo requer a transformação da linguagem do participante em linguagem científica, mantendo a ênfase do fenómeno descrito; o último passo é a síntese e associação das unidades de significados, chegando ao núcleo do significado do fenómeno (Giorgi, 2006).

$\mathrm{O}$ anonimato dos motoristas foi mantido, e a sua identificação foi dada pela sigla PTC, que significa profissional do transporte coletivo, somado a um número arábico que correspondeu à organizaçáo da investigadora, garantindo a pronta identificação por parte, apenas, da investigadora. Foram selecionados excertos da transcrição das entrevistas considerados essenciais ao desvelamento dos objetivos propostos. Utilizou-se a compreensão fenomenológica para que os resultados fossem apresentados por unidades de significação, agrupados pelo conteúdo destacado dos relatos dos sujeitos e analisados com base em estudos sobre o tema, garantindo a singularidade das vivências, subsidiados por conceitos do pensamento fenomenológico (Hilkner, Beck, Tanaka, \& Dini, 2019).

\section{Resultados}

Os participantes, na sua maioria, são homens, somando 22, no total, e duas mulheres. A média de idade foi de 41,6 anos. Todos os participantes apresentaram mais de dois cursos na área dos 
transportes. Oito motoristas relataram problemas na coluna vertebral e constantes dores lombares; 12 motoristas referiram sentir dores de cabeça diariamente; um motorista destacou as dores nas pernas como uma alteração na sua saúde, e outros quatro não relataram problemas de saúde. Todos os entrevistados relataram o uso de analgésicos e anti-inflamatórios pelo menos em 1dia da semana, além da medicação que a maioria já faz uso nos tratamentos de saúde. Nenhum motorista de autocarros faz terapia com psicólogo, e a principal justificativa é a rotina de trabalho semanal.

O tempo médio na profissão foi de 10 anos, e seis motoristas trabalham em linhas de autocarros municipais, enquanto 18 motoristas percorrem distâncias maiores nas linhas intermunicipais. Dezanove motoristas destacaram como aspeto incómodo no dia-a-dia o próprio trânsito.

As categorias que emergiram foram $\mathrm{O}$ trânsito é uma caixa de surpresas, o que expressa a imprevisibilidade quotidiana no contexto de trabalho dos motoristas de autocarros, e a segunda categoria foi $\mathrm{O}$ equilíbrio psicológico é necessário, sendo a constante busca pela paciência imprescindível ao trabalho, como um exercício de resistência às adversidades na direção e na relação com os demais motoristas e passageiros. Os motoristas descreveram episódios diários no exercício da sua profissão, especialmente a dificuldade dos demais, de diferentes veículos, para lidar com os autocarros no trânsito, e como o corpo deles reage ao dia-a-dia.

$\mathrm{Na}$ Categoria 1 destacam-se os seguintes relatos: "tem dia que é bom e tem dia que é totalmente horrível. Dá vontade de você largar tudo e ir pra sua casa e relaxar" (PTC 1, julho de 2017); "o trânsito tem algumas coisas que podiam mudar. Não fazem não eu não sei por quê. Cada dia é um dia, é uma caixa de surpresa, nada me surpreende mais" (PTC 2, julho de 2017); "tem que se acostumar com aquilo ali, né, porque o trânsito não é fácil, não. Não é fácil, mas ... Peço a proteção de Deus, vai embora ..." (PTC 6, julho de 2017); "trânsito, é normal, quando eu entrei eu sabia o que eu iria enfrentar, eu procuro fazer o máximo de modo tranquilo" (PTC12, agosto de 2017); "não pode prever, uma hora você está tranquila em outra as pessoas fazem coisas que não devem, as vezes tenho dificuldades no trânsito as pessoas estão displicentes não tem cuidado com a vida, com os pedestres" (PTC
14, agosto de 2017).

$\mathrm{Na}$ Categoria 2 destacam-se os seguintes relatos: "hoje em dia, se você não tiver uma calma, uma paciência, né, na rua, é complicadíssimo" (PTC 3, julho de 2017);

É meio complicado, muito carro na pista e os motoristas estão mal-educados, você pede passagem, eles não dão, jogam o carro em cima, xingam. Então, você tem que tentar manter a calma, o que não é fácil. $\mathrm{O}$ ser humano poderia ter um pouco mais de educação. Tenho muita dor na cabeça. Eu fico muito nervoso (PTC 4, julho de 2017); o estresse é muito grande. $\mathrm{O}$ dia a dia do motorista é sempre uma experiência nova. $\mathrm{O}$ estresse vem de nós. Não termos um tempo para gente ... No fim, o motorista, se ele não cuidar do lado mental, se ele não tiver uma higiene mental, ele acaba infartando, porque é muito complicado. Eu sinto muitas dores de cabeça e no corpo. (PTC 05, julho de 2017);

eu trabalho com dores na coluna. É a posição do banco. Eu comparo o trânsito com a vida: eu acho que a nossa vida tem momentos de muitas alegrias, e têm momentos difíceis. Nossa vida é uma via, e quando chegar ao final, eu vou fazer a manobra e vou voltar, e botar a minha cabeça no lugar. (PTC 07, julho de 2017);

"Minha vivência no trânsito é muito estressante, principalmente nos horários de pico, todo mundo querendo chegar no seu trabalho, todo mundo atrasado, a falta de educação, um querendo passar na frente do outro" (PTC 8, agosto de 2017);

Se você acender, piscar um farol, buzinar pra ele, manda passar por cima. E aí, a gente segura, liga o alerta pra dizer que o carro está lá na frente, vai lá na frente. Ligo o alerta, eu tento sair dele pra ir embora. (PTC 9, agosto de 2017);

"Por você ser um profissional você tem que ceder, se você bater independente de estar certo ou estar errado eu procuro ser o mais paciente possível, é aí que vem o estresse" (PTC 10, agosto de 2017); "O trânsito é caótico acho que os motoristas têm a pior qualidade na condição de trabalho" (PTC11, agosto de 2017); “Eu procuro ter paciência, porque o trânsito hoje em dia está muito estressante, e eu falo com certeza que eu digo trânsito para mim é desde a hora 
que eu levanto, até a hora de dormir, porque é movimento" (PTC 13, agosto de 2017); “eu procuro fazer o máximo de modo tranquilo, mas tem dias que a gente está mal, problema familiar, triste, estressado, mas eu procuro fazer as coisas sempre dentro do eixo, tudo certinho" (PTC 15, setembro de 2017); "eu faço o possível para fazer o horário, mas se não der, tudo bem" (PTC 16, setembro de 2017);

Tudo parado não tem opção, é uma realidade muito difícil o meu segredo é a paciência, eu fico contando no dedo um-dois-três-quatrocinco, volta de novo porque senão você faz besteira, não vai resolver ficar nervoso, vai ter um infarto ali, não vai adiantar nada. (PTC 17, outubro de 2017);

"é só trabalhar com amor que o trânsito não vai te estressar" (PTC 18 outubro de 2017); "tem gente que já acorda estressada e desconta na gente que está no volante. Me incomoda a falta educação nos passageiros" (PTC19 outubro de 2017); "às vezes, eu vejo que (risada) o trânsito, ele é violento. Então, a gente tem que, tem que ... Desacelerar" (PTC 20, novembro de 2017); "eu me incomodo com a falta de educação dos passageiros. O tratamento deles não é bom, deixa meu dia ruim" (PTC 21, novembro de 2017); "ah, tem clientes que me tratam com ignorância. Falta respeito e educação” (PTC 22, dezembro de 2017); "tenho até tristeza em falar. Os passageiros nos tratam muito mal" (PTC 23, dezembro de 2017); "as vezes o acidente acontece pelo apavoramento do motorista, sempre tem que manter a calma, entendeu? Gosto de olhar para trás e ver os passageiros dormindo, porque eu sinto que eles confiam em mim" (PTC 24, dezembro de 2017).

O comportamento dos demais condutores apareceu como um aspeto stressante para estes motoristas. $\mathrm{O}$ trânsito e as condições dos assentos do autocarros são fonte de desgaste e dores para o corpo. O stress é um agravante para a insatisfação do motorista com a sua profissão. $\mathrm{O}$ desrespeito à ergonomia altera as dimensóes cognitivas e fisiológicas do trabalhador.

A busca pela paciência é um movimento interno constante dos motoristas participantes. A experiência ensinou-lhes que as consequências para a saúde mental podem ser um preço muito alto resultante da profissão.

\section{Discussáo}

O mal-estar gerado no interior do coletivo pode influenciar negativamente todo o dia de trabalho do motorista. $\mathrm{O}$ trabalhador continua a conduzir mesmo após o destrato dos passageiros.

Os desajustes nas relaçóes interpessoais do trabalho fragilizam o corpo do motorista, que pode somatizar o conflito. $\mathrm{O}$ trabalhador não dispóe de poder de decisão sobre quem entra no seu ambiente de trabalho (o autocarro), ficando vulnerável ao humor dos passageiros. A tarefa, frequentemente, não leva em conta as particularidades dos operadores (Quirino \& Villemor-Amaral, 2015). Elas precisam de ser realizadas mecanicamente, desconsiderando muitas vezes o estado emocional do motorista.

O desgaste mental está no cerne dos riscos à saúde. A perda de concentração, o aumento da agressividade, o choque com a realidade externa do motorista e a dificuldade interpessoal gerada pela falta de respeito dos colegas afetam a saúde do profissional.

As exigências internas das empresas causam stress nos profissionais. $\mathrm{O}$ tempo de profissão está relacionado com o aparecimento de stress, a perda do senso de humor, o mal-estar generalizado sem razão específica e o cansaço constante.

Sobre a situação dos trabalhadores rodoviários, destacamos a dos motoristas, eles não trabalham num local fixo: a sua jornada de trabalho é realizada nas agitaçóes do trânsito, além de não terem poder de decisão sobre quem frequenta a sua ferramenta de trabalho. Nos autocarros, a relação interpessoal com os clientes é necessária, porém é fonte de stress e sintomas no profissional. Conduzir um transporte coletivo é, ao mesmo tempo, uma atividade individual e coletiva - a razão do serviço prestado é transportar os clientes, porém, são inevitáveis os conflitos na seguinte relação: motorista-cliente. Esta traz reflexos na saúde.

A saúde humana tem vindo a apresentar alteraçôes pela forma como o processo de globalização e reestruturação produtiva se tem vindo a desenvolver, definindo o processo saúde-doença da população produtiva (Minayo, 2002). As transformaçóes que ocorrem nas esferas económicas, políticas, sociais e técnicas, presentes no trabalho, exercem forte domínio sobre a saúde dos trabalhadores. Quanto mais um ambiente se tornar desumano, mais difícil será manter a 
sobrevivência dos sujeitos que interagem neste espaço.

O cuidado é entendido como um modo de ser; sem o cuidado, deixa-se de ser humano. Esta é a fundamentação que se atribui ao tema em análise, de cunho filosófico; assim, a afirmação de que o cuidado é o que confere a condição de humanidade às pessoas é uma afirmação lógica. A enfermagem é a arte de cuidar (Polit \& Beck, 2011). A cura, muitas vezes, não é a consequência do cuidado, mas é sinónimo de compreensão da dor, da experiência do outro. $\mathrm{O}$ cuidado vivenciado na prática de enfermagem desvela $\mathrm{o}$ outro lado da profissão, o lado empático do que percebe e do que é percebido.

Para cuidar, é necessário conhecer, e é neste campo técnico-científico que o encontro entre motorista e enfermeiro perpassa o fazer de ambas as profissóes, visto que o motivo para consulta de enfermagem, no setor clínico da organização, transborda o sentido do sintoma ou da linguagem, na medida em que esse profissional (enfermeiro) considera o motorista como sujeito investido de um corpo que pensa e padece pela vivência de angústias e perigos do trânsito. $\mathrm{O}$ enfermeiro poderá ser reconhecido pela capacidade de compreender a necessidade de atendimento e construir o encontro humanizado com qualificaçáo na escuta e parceria colaborativa com o motorista de autocarros.

Neste contexto, os recursos humanos, representados pelos setores de psicologia nas organizaçôes, não se responsabilizam apenas pela admissão e demissão de motoristas de autocarros e demais funcionários, mas configuram um espaço de atendimento às necessidades dos mesmos, demandas estas que vão desde um desabafo a traumas vivenciados na atividade laboral.

O fenómeno de conduzir pode ser percebido fora da mobilidade urbana. O mundo e o corpo do motorista de autocarros é afetado pelas condiçóes de trabalho e pelo stress (Martins et al., 2014). A busca pelo equilíbrio entre as demandas laborais e psicológicas é um exercício diário para o psiquismo dos motoristas de autocarros. Estes, esforçam-se para manter o controlo das suas emoções a fim de não prejudicarem o serviço e o convívio com os passageiros, e concluírem o dia de trabalho positivamente (Zamboni \& Barros, 2016). A escala de trabalho destes profissionais pode variar de acordo com a necessidade da empresa. A atividade acaba por exigir dedicação exclusiva, sendo muitas vezes a única fonte de rendimento deste trabalhador.

A perceção é a porta de entrada do mundo na consciência. É a partir dela que o sujeito tem revelados para si os factos e fenómenos. Ela é singular e, assim, cada um possui a sua, em perspetiva. Na perceção, tem-se um fenómeno existencial. A vida não se resume nas explicaçôes científicas, a perceção vivenciada também deve ser valorizada. $\mathrm{O}$ objeto percebido pode ser uma referência para o corpo. Após o sentir, o novo pensamento deverá ser entendido; a reflexão estará segura de ter encontrado o centro do fenómeno se ela for igualmente capaz de esclarecer a sua inerência vital e sua intenção racional (Merleau-Ponty, 2014). Desta forma, o objeto trânsito é vivenciado de forma particular por cada um dos seus componentes, e aqui coloca-se em destaque a participação dos motoristas de autocarros.

Na perceção há uma pluralidade de reflexôes, lembranças, esquecimentos, silêncios e vozes. Essa referida pluralidade existe não apenas entre dois sujeitos, mas até mesmo em um, apenas: o mesmo ser humano pode perceber um mesmo fenómeno de formas distintas; pois ele e tudo que o forma estão sujeitos à subjetividade, à temporalidade e à forma de ser e estar no mundo em que se encontra (Merleau-Ponty, 2014). $\mathrm{O}$ olhar do sujeito não é a apenas a consequência de luzes refletidas na córnea; o olhar em fenomenologia é revisitar o mundo, é sentido de um comportamento. Nada é mais difícil do que saber, ao certo, o que se vê a conduzir a própria consciência. Ela percebe o mundo, percebe além da visão, busca compreender o sentido das experiências, das emoçóes (Silva, 2017).

A consciência humana transcende a localização neurológica; ela é dinâmica, adapta-se ao que conhece. $\mathrm{O}$ fenómeno consciência apresenta-se refletido no pensamento que se transforma em ato. Podemos existir além da perceção: se é corpo, se é parte do mundo, se é o sentir, se é o olhar (Merleau-Ponty, 2014).

O olhar fenomenológico está implicado à consciência imediata sobre o que é percebido, sobre o fenómeno, sobre o mundo, sobre o corpo fenómeno, por exemplo, que é o próprio sujeito, uma interação de estar-no-mundo. No âmbito da saúde, as contribuiçóes da fenomenologia estáo relacionadas com o cuidar-pesquisar-cuidar; é necessário considerar o sujeito e a sua fala nas 
experiências vividas por ele próprio. As variáveis que intervêm no quotidiano do motorista de autocarros, incluindo as relaçóes interpessoais problemáticas, as cobranças organizacionais e, não se pode ignorar, as cobranças do si mesmo, são geradoras de stress e alteraçóes na saúde. O sofrimento no trabalho é realidade, e é necessário resgatar o trabalhador, motivando-o a seguir adiante e provendo um ambiente laboral salubre e satisfatório (Alcantara et al., 2016). É imperativo ter em conta a singularidade de cada indivíduo, porque a sua subjetividade é uma manifestação do viver total, mas também é preciso saber que a experiência e a vivência de uma pessoa ocorrem no âmbito social e são contextualizadas e envolvidas pela cultura do grupo em que ela se insere.

A limitação deste estudo correspondeu ao seu próprio ineditismo: as pesquisas fenomenológicas na saúde ainda são escassas, principalmente ao tratar-se de saúde do trabalhador. Este é o primeiro trabalho de tese que aborda a temática do motorista de autocarros com bases na metodologia fenomenológica. As pesquisas que envolvem a saúde do trabalhador utilizam, na sua maioria, métodos quantitativos que expressam a incidência de doenças, entre outras variáveis. Sendo a perceção um constructo base da Fenomenologia, a proposta desta investigação é interpretar segundo as perceçóes dos trabalhadores, a partir da vivência neste contexto de trabalho, a forma como os afeta a nível físico e emocional. A fim de superar esta limitação, buscou-se transformar em linguagem fenomenológica as percepçóes dos trabalhadores de transportes coletivos. A fenomenologia, com a sua sensibilidade filosófica, prioriza o sujeito como humano, considerando todo o seu contexto de vida.

\section{Conclusão}

Os efeitos negativos do trabalho em transportes coletivos, seja pelas surpresas que ocorrem no dia-a-dia, ou pelo stress gerado pelos relacionamentos interpessoais com colegas de profissão ou passageiros, colocam em questáo a mobilidade urbana, apontando para a importância do envolvimento das empresas de autocarros em fornecer condições favoráveis para a prática da atividade laboral, como um ambiente adequado e, também, açôes que promovam a saúde do motorista de autocarros. Destaca-se a necessidade de o próprio trabalhador ter um olhar sensível para a sua saúde, procurando ajuda não apenas para o corpo físico, que manifesta sintomas que influenciam a força para o trabalho, mas, também, para o corpo psíquico. Sem a presença da saúde mental, torna-se inviável estar no mundo do trabalho e realizar o transporte de vidas com responsabilidade e segurança.

Ressalta-se que o governo deve procurar melhorar as vias de trânsito, bem como facitiliar o acesso à saúde e implementar melhores condições de trabalho no que toca a políticas públicas de atenção aos profissionais dos transportes.

As ciências da saúde possuem protagonismo no cuidado aos motoristas de autocarros, pois é necessária a preservação do corpo como parte do processo de trabalho e a alteração da lógica organizacional, que prioriza a produção e descuida do trabalhador. Destarte, considera-se que mais investigaçóes com motoristas de autocarros no papel de protagonistas são necessárias para que haja superaração da sua invisibilidade nas cidades e no seu contexto urbano.

Dar voz a estes profissionais, trazendo à luz o que acarreta o seu sofrimento, e reconhecer as suas necessidades, contribuirá para a prevenção de doenças físicas e psicológicas, bem como de acidentes de trânsito.

\section{Financiamento}

Esta pesquisa é financiada pela Fundação de Amparo à Pesquisa do Estado do Rio de Janeiro - FAPERJ.

\section{Referências bibliográficas}

Alcantara, V. C., Silva, R. M., Pereira, E. R., \& Silva, M. A. (2016). A qualidade de vida para motoristas de autocarros: Entre a saúde e o trabalho. Revista Portuguesa de Enfermagem de Saúde Mental, (spe. 4), 101106. doi:10.19131/rpesm.0148

Carel, H., \& Meacham, D. (2013). Phenomenology and naturalism: Examining the relationship between human experience and nature. New York, NY: Cambridge University Press.

Dale, G. A. (1996). Existential phenomenology: Emphasizing the experience of the athlete in sport psychology research. The Sport Psychologist, 10(4), 307-321. doi: 10.1123/tsp.10.4.307

Giorgi, A. (2006). Difficulties encountered in the ap- 
plication of the phenomenological method in the social sciences. Análise Psicológica, 24(3), 353-361. doi:S0870-82312006000300009

Hilkner, S. H, Beck, A. R., Tanaka, E. Z, \& Dini, A. P. (2019). Perceçóes de irmáos de crianças hospitalizadas por doença crónica. Revista de Enfermagem Referência, 4(20), 77-86. doi:10.12707/RIV18074

Ismail, A. R., Abdullah, S. N. A., Abdullah, A. A., \& Deros, B. (2015). A descriptive analysis of factors contributing to bus drivers' performances while driving: A case study in Malaysia. International Journal of Automotive and Mechanical Engineering, 11(1), 2430-2437. doi:10.15282/ijame.11.2015.23.0204

Martins, F. F., Lopes, R. M ., \& Farina, M. (2014). Nível de estresse e principais estressores do motorista de transporte coletivo. Boletim - Academia Paulista de Psicologia, 34(87), 523-536. Recuperado de http:// pepsic.bvsalud.org/scielo.php?script=sci_arttext\&pi$\mathrm{d}=$ S1415-711X2014000200014

Matos, M. G., Moraes, L. F., \& Pereira L. Z. (2015). Análise do estresse ocupacional em motoristas de Coletivo Urbano na Cidade de Belo Horizonte. Revista Gestão \& Tecnologia, 15(1), 256-275. doi:10.20397/21776652/2015.v15i1.758

Merleau-Ponty, M. (2014). Fenomenologia da percepção. São Paulo, Brasil: Martins Fontes.

Minayo, M. C. (2002). Pesquisa social: Teoria, método e criatividade. Rio de Janeiro, Brasil: Vozes.

Polit, D. F., \& Beck, C. T. (2011). Fundamentos da pesquisa em enfermagem: Avaliação de evidências para a prática da enfermagem ( $7^{\mathrm{a}}$ ed.). Porto Alegre, Brasil: Artmed.
Quirino, G. S., \& Amaral, A. E. (2015). Relação entre estresse e agressividade em motoristas profissionais. Revista Psicologia e Saúde, 7(2), 125-132. Recuperado de http://pepsic.bvsalud.org/scielo.php?script=sci_arttext\&pid=S2177-093X2015000200006

Rajeshwar, B., Rajalakshmi, R., Nitin A. J., \& Umadevi, S. V. (2016). Hearing impairment and high blood pressure among bus drivers in Puducherry. Journal of Clinical and Diagnostic Research, 10(2), CC08-CC10. doi:10.7860/JCDR/2016/17361.7199

Silva, M. A., Teixeira, E. R., Pereira, E. R., Silva, R. M., Rocha, R. C., \& Rondon, S. O. (2019). Saúde como direito e cuidado de si: Concepçáo dos profissionais de enfermagem. Revista Brasileira de Enfermagem, 72(Supl. 1), 159-165. doi:10.1590/0034-7167-2018-0066

Silva, C. A. (2017). Merleau-Ponty, percepção e arte. Princípios: Revista de Filosofia, 24(43), 267-275. doi:10.21680/1983-2109.2017v24n43ID10983

Vinuto, J. (2014). A amostragem em bola de neve na pesquisa qualitativa: Um debate em aberto. Temáticas, 22(44), 203-220. Recuperado de https://pdfs. semanticscholar.org/cd8e/3ecb215bf9ea6468624149a343f8a1 fa8456.pdf

World Health Organization. (2013). Violence and injury prevention: Roadsafety in Brazil. Recuperado de https:// www.who.int/violence_injury_prevention/road_traffic/countrywork/bra/en/

Zamboni, J., \& Barros, M. E. (2016). Paradoxo da corporatividade: $\mathrm{O}$ motorista de como corpo coletivo. Psicologia Universidade de São Paulo, 27(2), 332340. doi:10.1590/0103-656420150027 
